\title{
Genetic and biochemical approaches towards unravelling the degradation of gallotannins by Streptococcus gallolyticus
}

Natalia Jiménez, Inés Reverón, María Esteban-Torres, Félix López de Felipe, Blanca de las Rivas and Rosario Muñoz*

\begin{abstract}
Background: Herbivores have developed mechanisms to overcome adverse effects of dietary tannins through the presence of tannin-resistant bacteria. Tannin degradation is an unusual characteristic among bacteria. Streptococcus gallolyticus is a common tannin-degrader inhabitant of the gut of herbivores where plant tannins are abundant. The biochemical pathway for tannin degradation followed by S. gallolyticus implies the action of tannase and gallate decarboxylase enzymes to produce pyrogallol, as final product. From these proteins, only a tannase (TanBsg $)$ has been characterized so far, remaining still unknown relevant proteins involved in the degradation of tannins.
\end{abstract}

Results: In addition to TanBsg, genome analysis of S. gallolyticus subsp. gallolyticus strains revealed the presence of an additional protein similar to tannases, TanAsg (GALLO_0933). Interestingly, this analysis also indicated that only S. gallolyticus strains belonging to the subspecies "gallolyticus" possessed tannase copies. This observation was confirmed by PCR on representative strains from different subspecies. In S. gallolyticus subsp. gallolyticus the genes encoding gallate decarboxylase are clustered together and close to $\operatorname{TanB}_{s g}$, however, $\operatorname{Tan} \mathrm{A}_{\mathrm{sg}}$ is not located in the vicinity of other genes involved in tannin metabolism. The expression of the genes enconding gallate decarboxylase and the two tannases was induced upon methyl gallate exposure. As TanB $B_{s g}$ has been previously characterized, in this work the tannase activity of $\operatorname{TanA}_{\mathrm{sg}_{\mathrm{g}}}$ was demonstrated in presence of phenolic acid esters. TanAsg showed optimum activity at $\mathrm{pH} 6.0$ and $37^{\circ} \mathrm{C}$. As compared to the tannin-degrader Lactobacillus plantarum strains, S. gallolyticus presented several advantages for tannin degradation. Most of the L. plantarum strains possessed only one tannase enzyme ( $\left(T a n B_{\llcorner p}\right)$, whereas all the $S$. gallolytcius subsp. gallolyticus strains analyzed possesses both $T_{a n} A_{S g}$ and $T a n B_{S g}$ proteins. More interestingly, upon methyl gallate induction, only the $\tan B_{L p}$ gene was induced from the L. plantarum tannases; in contrast, both tannase genes were highly induced in S. gallolyticus. Finally, both S. gallolyticus tannase proteins presented higher activity than their L. plantarum counterparts.

Conclusions: The specific features showed by S. gallolyticus subsp. gallolyticus in relation to tannin degradation indicated that strains from this subspecies could be considered so far the best bacterial cellular factories for tannin degradation.

Keywords: Streptococcus gallolyticus, Tannase, Gallate decarboxylase, Hydrolase, Gallotannins

\footnotetext{
* Correspondence: r.munoz@csic.es

Laboratorio de Biotecnología Bacteriana, Instituto de Ciencia y Tecnología de

Alimentos y Nutrición, ICTAN-CSIC, Juan de la Cierva 3, Madrid, Spain
} 


\section{Background}

Tannins are widespread in the plant kingdom, and are often found in woody, lignified tissues [1]. Tannins form weak, $\mathrm{pH}$-dependent and reversible associations with a range of substrates such as cellulose, proteins or enzymes, among others, often making the substrate resistant to microbial attack [2]. Several reports have suggested that the presence of tannins at less than 6\% dry matter of the herbivore diet may result in improved animal performance. In contrast, detrimental effects of condensed tannins in excess of $6 \%$ dry matter include decreased growth rate and body weight gain, perturbation of mineral absorption, and inhibition of digestive enzymes [3]. Therefore, some herbivores have developed mechanisms to overcome adverse effects of tannins, at least partly, through the presence of tannin-resistant microorganisms [4].

Streptococcus gallolyticus (formerly known as Streptococcus bovis biotype I) has been isolated as a tanninresistant bacterium from diverse habitats. It is a normal inhabitant of the rumen and has been isolated from feces of koalas, kangaroos, Japanese large wood mouse, cows, horses, pigs, and guinea pigs [5-7]. The presence of $S$. gallolyticus strains in the digestive tract of herbivores may play an essential role for the host in order to assimilate the tannin-rich diets from their natural habitats. The specific catabolic capacities of S. gallolyticus likely provide this bacterium a selective advantage to survive in the gut of herbivores, where tannins of plant origin are abundant. Therefore, a symbiotic relationship could exist between the animal host and the bacteria to counteract the antinutritional effect of dietary tannins [7].

S. gallolyticus strains hydrolyzed tannic acid to release gallic acid, which was subsequently decarboxylated to pyrogallol [8]. The proposed biochemical pathway for the degradation of tannins by $S$. gallolyticus implies the action of a tannase and a gallate decarboxylase enzyme to decarboxylate the gallic acid formed by tannase action [8]. Pyrogallol is formed as a final product from tannin biodegradation [8]. An identical pathway is also used by Lactobacillus plantarum strains to degrade tannins. The L. plantarum genes encoding tannase $\left(\tan B_{L p}\right.$, formerly called tanLp1) [9] and gallate decarboxylase (lpdBCD) [10] involved in tannin degradation have been identified. In addition, a second tannase gene $\left(\tan A_{L p}\right)$ present in some $L$. plantarum strains has been recently described [11]. Upon tannin induction, the expression of $\tan B_{L p}$ was induced, whereas $\tan A_{L p}$ expression was not affected [11]. Moreover, Tan $\mathrm{A}_{\mathrm{Lp}}$ has a specific activity ten times lower than the specific activity calculated for $\operatorname{TanB}_{\mathrm{Lp}}$ tannase.

Similarly to L. plantarum, the genome of S. gallolyticus UCN34 revealed unique features among streptococci related to its adaptation to the rumen environment such as its ability to degrade tannins [12]. Tannins must be degraded by the action of a tannase enzyme [13]. A gene encoding a nonsecreted protein similar to $\operatorname{TanB}_{\mathrm{Lp}}$ (GALLO_1609) was found in the S. gallolyticus UCN34 genome. This protein TanB $_{S g}$ (formerly called TanSg1) has been biochemically characterized recently [14]. In addition, another gene, GALLO_1609, encoding a 596amino acid long protein $43 \%$ identical to the tannase from Staphylococcus lugdunensis $\left(\operatorname{Tan}_{\mathrm{SI}}\right)$ [15] is present in the S. gallolyticus UCN34 genome. From the genes involved in tannin degradation in S. gallolyticus, only the $\tan B_{S g}$ gene encoding a tannase has been identified so far [14], remaining unknown the genes encoding the gallate decarboxylase enzyme as well as a putative second tannase enzyme. In this work, S. gallolyticus tannase and gallate decarboxylase encoding genes involved in tannin degradation have been identified and their expression comparatively studied. In addition a novel tannase has been characterized. These results provide new relevant insights into S. gallolyticus tannin degradation, a rare biochemical property among bacteria.

\section{Results and discussion}

Sequence analysis of S. gallolyticus tannase enzymes

The formerly Streptococcus bovis group is a large bacterial complex including different species frequently isolated from animals. In 2003, the physiological differentiation between species related to the complex and the clarification of their respective phylogenetic position was improved [16]. The updated classification included three subspecies: S. gallolyticus subsps. gallolyticus, S. gallolyticus subsp. pasteurianus, and S. gallolyticus subsp. macedonicus. These can be identified according to differential biochemical reactions. Among these biochemical tests, tannase activity was only described in S. gallolyticus subsp. gallolyticus strains. Only strains from this subspecies hydrolyze methyl gallate (tannase activity) and decarboxylate gallic acid to pyrogallol [16] (Figure 1).

The ability to degrade tannins is a specific attribute of S. gallolyticus subsp. gallolyticus deemed important in hostile environments, as tannins are toxic polyphenolic compounds that form strong complexes with proteins and other macromolecules. The S. gallolyticus subsp. gallolyticus UCN34 genome revealed the presence of two proteins similar to tannases, TanA Sg $_{\text {(GALLO_0933) and TanB }}$ (GALLO_1609). The tannase proteins from S. lugdunensis $\left(\operatorname{Tan} \mathrm{A}_{\mathrm{SI}}\right)$, L. plantarum $\left(\operatorname{Tan}_{\mathrm{Lp}}\right.$ and $\left.\operatorname{TanB}_{\mathrm{Lp}}\right)$ and S. gallolyticus $\left(\operatorname{Tan}_{\mathrm{Sg}}\right.$ and $\mathrm{Tan}_{\mathrm{Sg}}$ ) were aligned. The alignment revealed that two protein groups could be easily identified. TanA proteins, higher than $60 \mathrm{kDa}$ and possessing a cleavage site of a peptide signal, and TanB proteins, having around $50 \mathrm{kDa}$ of molecular size. The identity degree among TanA and TanB proteins is lower than 30\%. The comparison of the amino acid sequence of these tannase proteins with $\mathrm{TanB}_{\mathrm{Lp}}$, whose tridimensional structure have been recently solved [17], revealed that the residues 


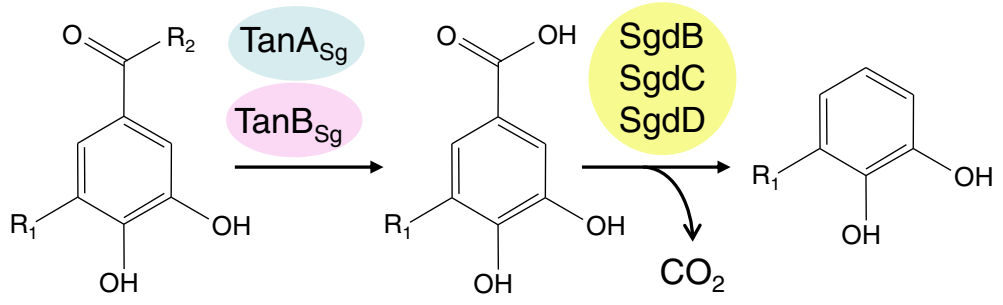

Figure 1 Schematic representation of tannin degradation pathway followed by $S$. gallolyticus. When $R_{1}$ is $(H)$ the represented compounds are a protocatechuate ester, protocatechuic acid, and catechol. When $\mathrm{R}_{1}$ is $(\mathrm{OH})$ the represented compounds are a gallate ester, gallic acid, and pyrogallol. $\mathrm{R}_{2}$ could be $\left(\mathrm{OCH} \mathrm{H}_{3}\right)$ representing methyl ester of gallic/protocatechuic acid, $\left(\mathrm{OCH}_{2} \mathrm{CH}_{3}\right)$ representing ethyl esters, $\left(\mathrm{OCH}_{2} \mathrm{CH}_{2} \mathrm{CH}_{3}\right)$ propyl esters, (glucose) as in tannic acid, or (epigallocatechin) in epigallocatechin gallate. Tan $A_{s g}$ and TanBsg represented tannase enzymes and SgdB, SgdC, and SgdD, represent the three subunits of gallate decarboxylase enzyme.

important for activity are conserved. All the analyzed proteins possessed the conserved motif Gly-X-Ser-X-Gly typical of serine hydrolases. The catalytic triad identified in the $\operatorname{TanB}_{\mathrm{Lp}}$ structure (Ser-163, Asp-419, and His-451) is only conserved in the TanB proteins. In both TanA proteins Asp-419 is substituted by a Gln residue. This amino acid variation was noticed previously and suggested that the conserved residue Asp-421 may fulfil the role of Asp-419 as the acidic residue of the catalytic triad [17]. The residues identified that make contacts with the three hydroxyl groups of gallic acid (Asp-421, Lys-343, and Glu357 , in $\left.\operatorname{TanB}_{\mathrm{Lp}}\right)$ are conserved in all the tannase proteins analyzed (Additional file 1: Figure S1A). When TanA proteins were compared identity degrees ranging from 44$50 \%$ were found (Additional file 1: Figure S1B). However, the identity among TanB proteins was more lower (32\%) (Additional file 1: Figure S1C).

As described previously for S. gallolyticus spp., only strains from the subspecies gallolyticus possess tannase activity [16]. However, it is not known if both tannase proteins are present in all the S. gallolyticus subsp. gallolyticus strains. Currently, the genomes of four S. gallolyticus subsp. gallolyticus strains are available (UCN34, ATCC 43143, ATCC BAA-2069, and TX2005 strains). A genome search revealed that the four strains possessed both tannase genes, TanAsg $\left(G A L L O \_0933\right.$, SGGB_0917, SGGBAA2069_c09070/80, and HMPREF9352_1611) or $\mathrm{TanB}_{\text {Sg }}$ (GALLO_1609, SGGB_1624, SGGBAA2069_c16370, and HMPREF9352_0937) in UCN34, ATCC 43143, ATCC BAA-2069, and TX2005 strains, respectively. In relation to $\mathrm{TanA}_{\mathrm{Sg}}$ from UCN34 strain, the proteins from TX2005 and ATCC 43143 strains exhibited 3 or 5 amino acid changes (data not shown). In addition, the Tan $\mathrm{A}_{\mathrm{Sg}}$ protein from ATCC BAA-2069 posses a mutation at position Tyr-230 which originates a stop codon, and therefore, a truncated protein (data not shown). In relation to $\mathrm{TanB}_{\mathrm{Sg}}$ proteins, protein from UCN34, ATCC 43143, and ATCC BBA-2069 strains were identical, however, protein from TX2005 strain showed 20 amino acid substitutions (data not shown). These results seem to indicate that all the strains from the S. gallolyticus subsp. gallolyticus possessed both, $\tan A_{S g}$ and $\tan B_{S g}$ genes. In order to associate the presence of these genes with the "gallolyticus" subspecies, DNA from different $S$. gallolyticus subspecies was used to amplify $\tan A_{S g}$ and $\tan B_{S g}$ genes. Oligonucleotides 803-804, and 774-775 amplified 1.7 and $1.4 \mathrm{~kb}$ DNA fragments from $\tan A_{S g}$ and $\tan B_{S g}$, respectively. From the strains assayed, only S. gallolyticus DSM 13808, S. gallolyticus subsp. gallolyticus UCN34, and S. gallolyticus subsp. gallolyticus DSM $16831^{\mathrm{T}}$ strains produce the two amplicons (Figure 2). No amplification was observed in strains belonging to the other $S$. gallolyticus subspecies, e.g. S. gallolyticus subsp. pasteurianus DSM $15351^{\mathrm{T}}$, and S. gallolyticus subsp. macedonius DSM $15879^{\mathrm{T}}$. These results indicated that, similarly to tannase activity, the presence of $\tan A_{S g}$ and $\tan B_{S g}$ genes seems to be specific for the subspecies gallolyticus.

Tannin-induced gene expression of the S. gallolyticus region involved in tannin degradation

The presence of both tannase genes in all the S. gallolyticus subsp. gallolyticus strains analyzed is in contrast with the uncommon presence of $\tan A_{L p}$ among L. plantarum strains. Only 4 strains out of $29 \mathrm{~L}$. plantarum strains analyzed possessed both tannase genes. Another significant difference among L. plantarum and S. gallolyticus strains is the organization of the genes involved in tannin degradation. In L. plantarum the genes encoding gallate decarboxylase $(l p d C$, and $l p d B D)$ are separated in the chromosome by more than $1 \mathrm{Mb}$ [10]; however in S. gallolyticus, the genes encoding gallate decarboxylase are clustered together ( $s g d C B D$ or GALLO_1613, GALLO_1612, and GALLO_1611, respectively) (Figure 3). Regarding the region involved in tannin degradation, all the currently available $S$. gallolyticus genomes displayed the same genetic organization as the S. gallolyticus UCN34 strain (Figure 3). In S. gallolyticus strains, TanA ${ }_{S g}$ and $\mathrm{TanB}_{\mathrm{Sg}}$ are separated from 691 (TX2005 strain) to $750 \mathrm{~kb}$ (ATCC BAA-2069 strain). Similarly to L. plantarum, TanB is located close to subunit $C$, the catalytic 
B
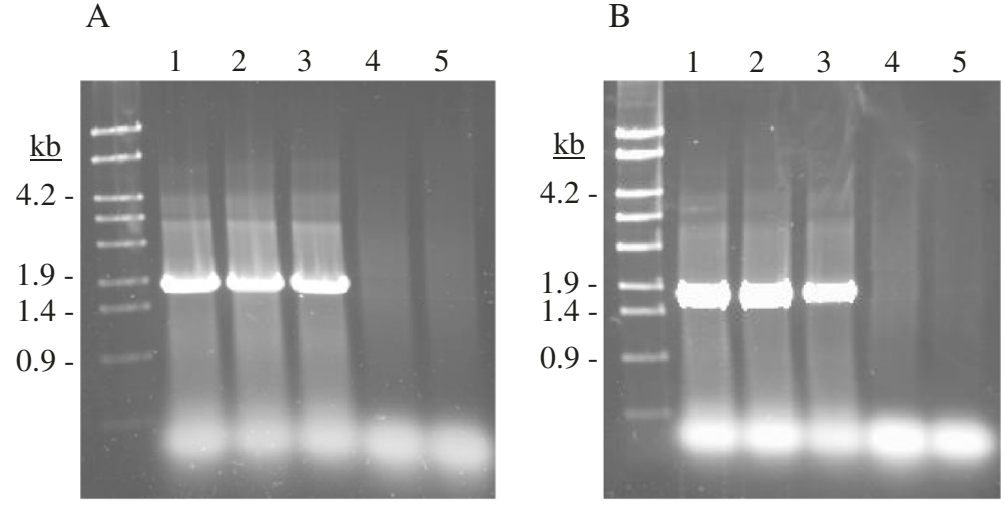

Figure 2 PCR amplification of tannase encoding genes from several S. gallolyticus strains. (A) Amplification of 1.7-kb DNA fragment of $\tan A_{s g}$ with oligonucleotides 803-804. (B) Amplification of 1.4-kb $\tan B_{S g}$ fragment with oligonucleotides 774-775. Chromosomal DNA from the following S. gallolyticus strains was used for PCR amplification: S. gallolyticus DSM 13808 (1), S. gallolyticus subsp. gallolyticus DSM 16831 ${ }^{\top}$ (2), S. gallolyticus subsp. gallolyticus UCN34 (3), S. gallolyticus subsp. pasteurianus DSM 15351 ${ }^{\top}$ (4), and S. gallolyticus subsp. macedonius DSM $15879^{\top}$ (5). PCR fragments were subject to agarose gel electrophoresis and stained with Gel Red. Left lane, $\lambda$-EcoT14l digest (Takara). Numbers indicated some of the molecular sizes (in kb).

subunit of the gallate decarboxylase. However, TanA is not located in the vicinity of other genes involved in the metabolism of tannins in L. plantarum and S. gallolyticus. The different chromosomal location of both tannase genes could indicate a different function and regulation.

In order to know the specific physiological role of both S. gallolyticus tannases the study of their synthesis under the presence of a substrate could provide relevant data. As tannase and gallate decarboxylase are involved in tannin degradation, the relative expression of their encodinggenes under methyl gallate exposure was studied. S. gallolyticus UCN34 cultures were induced for $10 \mathrm{~min}$ by the presence of $15 \mathrm{mM}$ methyl gallate as potential tannase substrate. Figure 4 shows the relative expression levels of $\tan A_{S g}, \tan B_{S g}$, and $s g d C B D$ genes under methyl gallate exposure. The highest induction was observed in the genes encoding gallate decarboxylase, $s g d C, s g d B$ and $s g d D$ which increased their expression 507, 90 and 54 times, respectively. Similarly, $\tan A_{S g}$ and $\tan B_{S g}$ genes were induced 14- and 6-fold, respectively. This result is in contrast with the expression pattern observed on the equivalent tannase proteins from $L$. plantarum since the presence of $15 \mathrm{mM}$ methyl gallate slightly induces (about 3-fold) the expression of $\tan B_{L p}$ gene. The expression behaviour observed in S. gallolyticus UCN34 allow us to assume that, in the presence of substrate, all the genes involved in tannin degradation were highly induced.

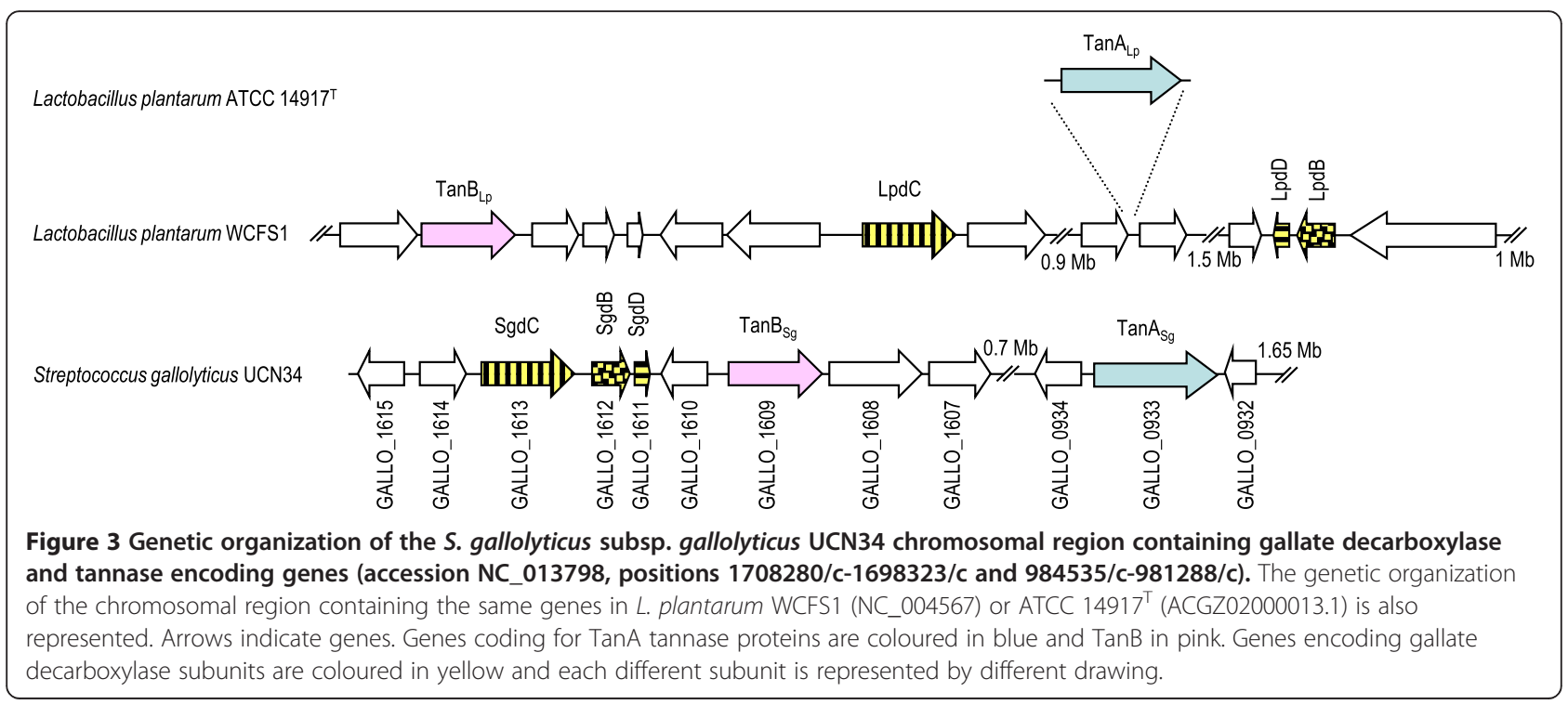




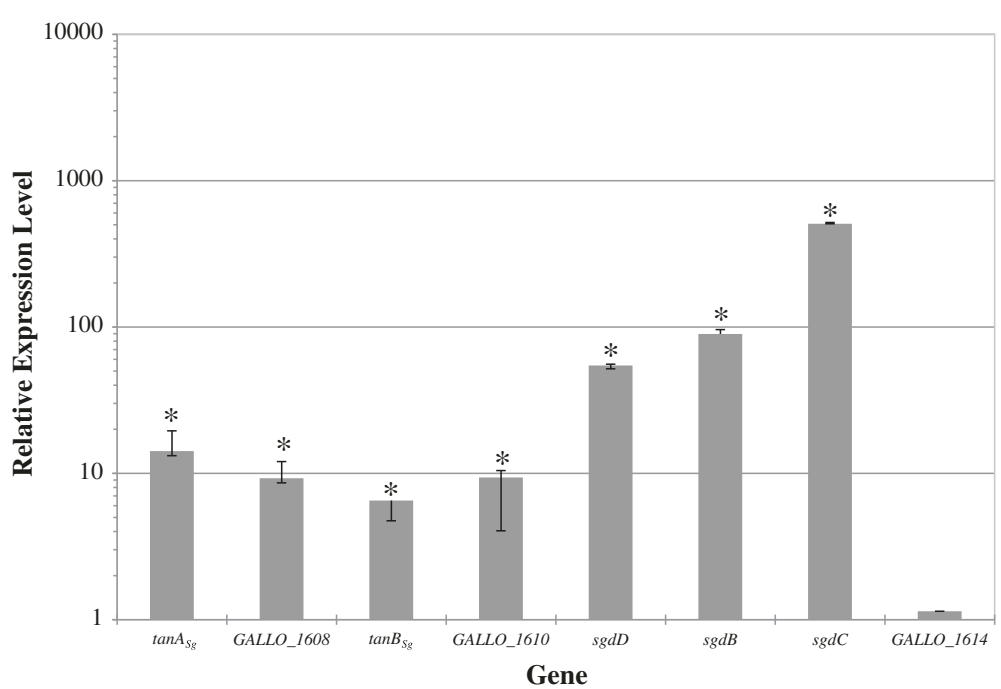

Figure 4 Comparison of the relative expression levels of tannase and gallate decarboxylase genes in response to methyl gallate exposure. Relative expression levels in $15 \mathrm{mM}$ methyl gallate were calculated with the 7500 Fast System relative quantification software using S. gallolyticus 165 rRNA gene as endogenous gene and the growth in the absence of methyl gallate as growth condition calibrator. The experiments were done in triplicate. The mean value and the standard error are shown. Asteriks indicate a $p$ value $<0.1$.

\section{Biochemical properties of S. gallolyticus UCN34 TanA $A_{S g}$ tannase}

When $\operatorname{TanB}_{\mathrm{Lp}}$ was the only tannase described from L. plantarum, homology searched allowed us to identify $\tan B_{S g}$ (GALLO_1609). The gene was cloned and expressed in $E$. coli, and the recombinant $\mathrm{TanB}_{\mathrm{Sg}}$ protein was biochemically characterized [14]. The data indicated that, as compared to $\mathrm{TanB}_{\mathrm{Lp}}$, TanB $\mathrm{Sg}$ possesses remarkable biochemical properties. TanB $\mathrm{B}_{\mathrm{Sg}}$ has a specific activity $41 \%$ higher than $\operatorname{TanB}_{\mathrm{Lp}}$, and displays optimum activity at $\mathrm{pH}$ 6-8 and $50-70^{\circ} \mathrm{C}$, showing high stability over a broad range of temperatures [14]. However, in relation to its substrate range and contrarily to $\mathrm{TanB}_{\mathrm{Lp}}$, only esters with a short aliphatic alcohol were effectively hydrolyzed by

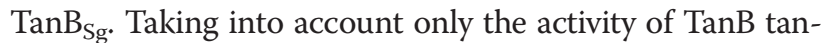
nases, it seems that $S$. gallolyticus could hydrolyze tannins more efficiently than $L$. plantarum strains.

Recently it has been described that in a few L. plantarum strains, a second tannase gene $\left(\tan A_{L \mathrm{p}}\right)$ could be found [11]. Compared to $\operatorname{TanB}_{\mathrm{Lp}}$, the Tan $\mathrm{A}_{\mathrm{Lp}}$ protein presented ten times lower specific activity, and showed differences in optimal $\mathrm{pH}$ and temperature. In order to demonstrate the functionality of Tan $\mathrm{A}_{\mathrm{Sg}}$ protein, and to know its biochemical properties and relevance on tannin degradation, the $\tan A_{S g}$ gene was expressed in $E$. coli under the control of an IPTG inducible promoter. Cell extracts were used to detect the presence of overproduced proteins by SDSPAGE analysis. Whereas control cells containing the pURI3-TEV vector did not show protein overexpression, an overproduced protein with a molecular mass around $63 \mathrm{kDa}$ was apparent with cells harbouring pURI3-TEVTanA $_{\text {Sg }}$ (Figure 5). Since the cloning strategy yields a
His-tagged protein variant, S. gallolyticus pURI3-TEVTan $A_{S g}$ could be purified on an immobilized metal affinity chromatography (IMAC) resin. The recombinant protein was eluted from the resin at $150 \mathrm{mM}$ imidazole, and observed as single band on 10\% SDSPAGE (Figure 5).

To demonstrate tannase activity, the $\mathrm{Tan}_{\mathrm{Sg}}$ protein purified by affinity chromatography was incubated in the presence of different esters of gallic acid. As expected for a tannase enzyme, Tan $\mathrm{A}_{\mathrm{Sg}}$ was able to hydolyze esters from gallic acid, confirming their tannase activity (Figure 6-1). Tan $A_{S g}$ hydrolyzes methyl, ethyl and propyl gallate, but similarly to $\operatorname{TanB}_{\mathrm{Sg}}[14]$ and $\operatorname{TanA}_{\mathrm{Lp}}$ [11], was unable to hydrolyze esters having an alcohol substituent as long as lauryl, which was hydrolyzed by $\operatorname{TanB}_{\mathrm{Lp}}$ [18]. As

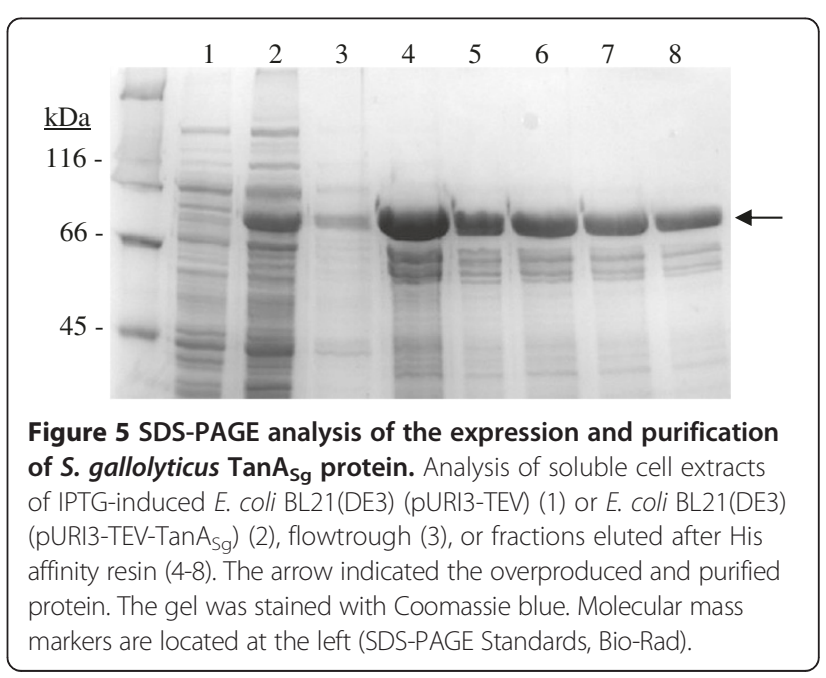



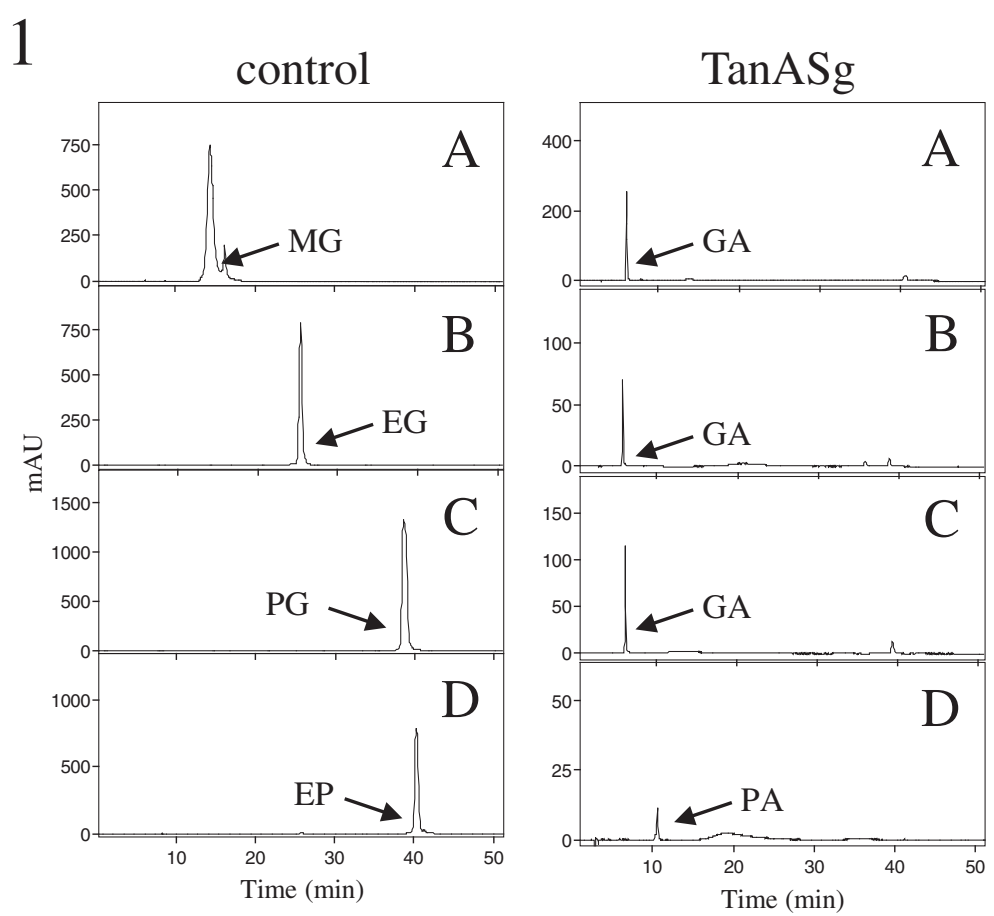

2
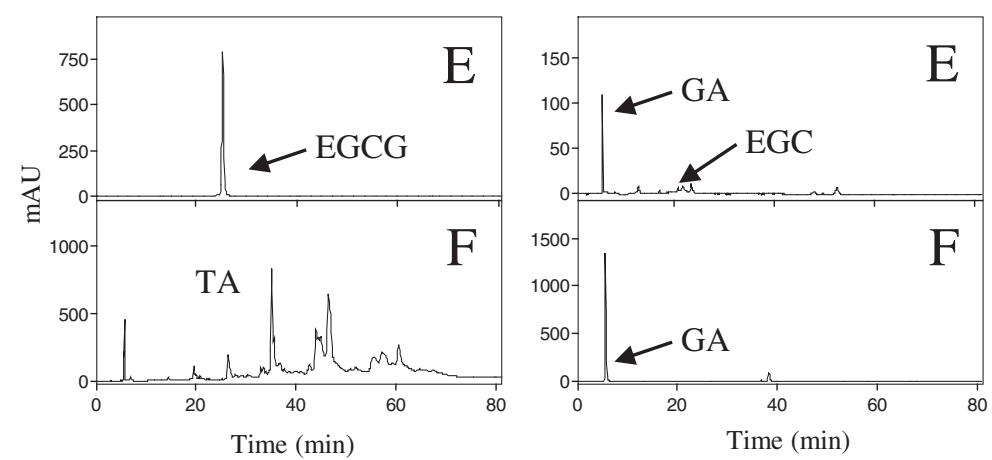

Figure 6 Tannase activity of S. gallolyticus Tan $A_{s g}$ protein against simple phenolic esters (1) and complex tannins (2). Hydrolase activity of purified Tan $A_{s g}$ protein was analyzed on triplicate and compared with control reactions on which the enzyme was omitted. HPLC chromatograms of TanA $\mathrm{sg}_{\mathrm{g}}(100 \mu \mathrm{g})$ incubated in $1 \mathrm{mM}$ of methyl gallate (A), ethyl gallate (B), propyl gallate (C), ethyl protocatechuate (D), epigallocatechin gallate (E), and tannic acid (F). The methyl gallate (MG), ethyl gallate (EG), propyl gallate (PG), ethyl protocatechuate (EP), epigallocatechin gallate (EGCG), tannic acid (TA), gallic acid (GA), protocatechuic acid (PA), and epigallocatechin (EGC) detected are indicated. The chromatograms were recorded at $280 \mathrm{~nm}$.

a general rule of the bacterial tannases described so far, a protocatechuate ester (ethyl protocatechuate) was also hydrolyzed by $\mathrm{TanA}_{\mathrm{Sg}}$ [18]. Esters from other phenolic acids assayed were not hydrolyzed (data not shown). These results confirmed that $\operatorname{Tan}_{S g}$ is a functional tannase with a substrate range resembling the bacterial tannases described previously $[11,14,18]$.

Different dietary plant varieties produce different types and quantities of phenolic compounds [19]. As the digestive tract of herbivores probably contains different tannins, we focused our studies on the relatively well-define commercially available preparations, tannic acid and epigallocatechin gallate. Tannic acid is almost exclusively formed by poly-galloyl glucose, and gallic acid was observed as the final product of $\mathrm{TanA}_{\mathrm{Sg}}$ activity on tannic acid (Figure 6-2). Similarly, gallic acid was released from epigallocatechin as a result of the action of $\mathrm{TanA}_{\mathrm{Sg}}$ on epigallocatechin gallate. These results confirmed the capacity of $\mathrm{TanA}_{\mathrm{Sg}}$ to degrade dietary tannins.

Once the tannase activity of $\mathrm{TanA}_{\mathrm{Sg}}$ was confirmed, their biochemical properties were determined. Since tannase catalyzes the hydrolysis of the galloyl ester linkage 
releasing gallic acid, the activity of tannase could be measured by estimating the gallic acid formed by the enzyme action [20]. A rhodanine specific method for the detection of gallic acid was used for a reliable quantification of tannase activity [21]. Rhodanine reacts with the vicinal hydroxyl groups of gallic acid to give a red complex with a maximum absorbance at $520 \mathrm{~nm}$. Rhodanine assay was used to determine the specific activity of $\operatorname{Tan} A_{\mathrm{sg}}$. Using methyl gallate as substrate, the specific activity of TanA $_{\text {Sg }}$ was $256 \mathrm{U} / \mathrm{mg}$, 55\% or $37 \%$ lower than the specific activity of $\operatorname{TanB}_{\mathrm{Sg}}\left(577 \mathrm{U} / \mathrm{mg}\right.$ ) or $\operatorname{TanB}_{\mathrm{Lp}}$ (408 U/mg); however, it was more than 6 times higher than the activity of the equivalent protein from $L$. plantarum, Tan $\mathrm{A}_{\mathrm{Lp}}$ (39 U/mg). These activity data indicated that S. gallolyticus strains have more potential to degrade tannins than L. plantarum strains. These activity data indicated that S. gallolyticus strains have more potential to degrade tannins than L. plantarum strains. Firstly, in L. plantarum only a small number of strains possessed $\tan A_{L p}$ gene, an inducible gene, whereas all the $S$. gallolytius subsp. gallolyticus strains analyzed so far possesses both tannase genes, being the two genes inducible by gallate esters. More importantly, tannases from S. gallolyticus possess higher specific activity than their counterparts from L. plantarum. A roughly estimation shows that $S$. gallolyticus strains bearing TanA $A_{S g}$ and $\mathrm{TanB}_{\text {Sg }}$ posses a two-fold higher tannase activity than most L. plantarum strains possessing only $\mathrm{TanB}_{\mathrm{Lp}}$ tannase.

In order to known if Tan $A_{S g}$ possesses additional valuable biochemical features, its optimal $\mathrm{pH}$ and temperature was analyzed. The biochemical characterization of $\operatorname{Tan} A_{S g}$ revealed an optimal $\mathrm{pH}$ around 6 , being also highly active at $\mathrm{pH}$ 6-8 (Figure 7A). This optimal $\mathrm{pH}$ is slightly lower than that reported for $\mathrm{TanB}_{\mathrm{Lp}}$ (optimal $\mathrm{pH}$ 7.0-8.0) $[9,18]$, but similar than that of $\mathrm{TanB}_{\mathrm{Sg}}[14]$ and $\operatorname{TanA}_{\mathrm{Lp}}$ [11]. The optimum temperature for activity is $37^{\circ} \mathrm{C}$, however the enzyme also exhibited very high activity at higher temperatures (Figure $7 \mathrm{~B}$ ). At $65^{\circ} \mathrm{C}$ Tan $\mathrm{A}_{\mathrm{Sg}}$ showed more than $80 \%$ of the maximum activity. Tan $\mathrm{A}_{\mathrm{Sg}}$ is able to hydrolyze the substrate (methyl gallate) at high temperatures. In addition, $\mathrm{TanA}_{\mathrm{Sg}}$ showed an improved thermal stability compared to $\mathrm{TanB}_{\mathrm{Lp}}$, since it retained more than $70 \%$ of the maximal activity after $18 \mathrm{~h}$ incubation at $37^{\circ} \mathrm{C}$ (Figure 7C). Non-ionic detergents showed different effect on TanA $A_{\text {Sg }}$ activity. Whereas Triton-X-100 did not affect activity, Tween-80 greatly increased tannase activity (Figure 7D). Similarly to $\mathrm{TanB}_{\mathrm{Lp}}$, among metal ions, $\mathrm{Ca}^{2+}$ and $\mathrm{K}^{+}$increased and $\mathrm{Hg}^{2+}$ greatly inhibited TanA $\mathrm{Ag}_{\mathrm{Sg}}$ activity [18]. The ions $\mathrm{Zn}^{2+}$ and $\mathrm{Mg}^{2+}$ partially inhibited the enzyme. The activity of $\operatorname{Tan}_{\mathrm{Sg}}$ was also significantly inhibited by $\beta$-mercaptoethanol (Additional file 2: Table S1).

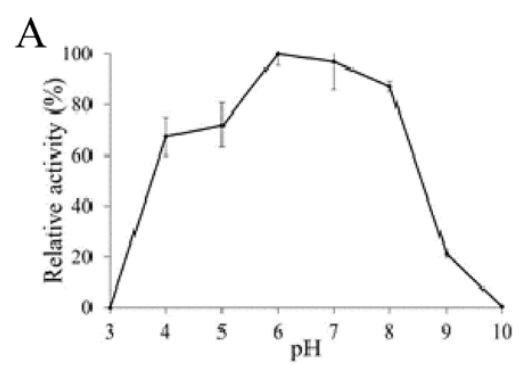

C

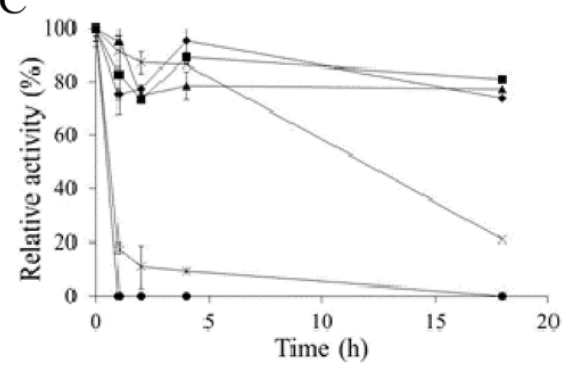

$\mathrm{B}$

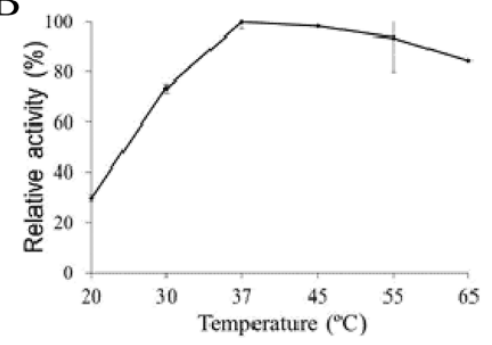

$\mathrm{D}$

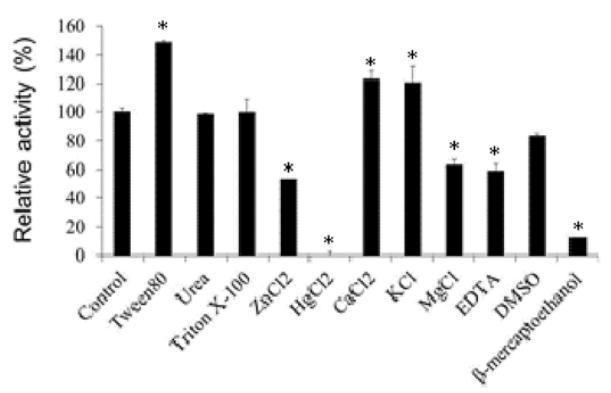

Figure 7 Some biochemical properties of $\operatorname{Tan}_{\mathbf{s}_{\mathbf{g}}}$ protein. (A) Relative activity versus $\mathrm{pH}$. (B) Relative activity of Tan $\mathrm{A}_{\mathbf{s g}}$ versus temperature. (C) Thermal stability of $\operatorname{TanA}_{\text {sg }}$ after preincubation at $22^{\circ} \mathrm{C}$ (filled diamond), $30^{\circ} \mathrm{C}$ (filled square), $37^{\circ} \mathrm{C}$ (filled triangle), $45^{\circ} \mathrm{C}$ (cross), $55^{\circ} \mathrm{C}$ (star), and $65^{\circ} \mathrm{C}$ (filled circle) in phosphate buffer (50 mM, pH 6.5); at indicated times, aliquots were withdrawn, and analyzed as described in the Methods section. The observed maximum activity was defined as 100\%. (D) Relative activity of Tan $\mathrm{Asg}_{\mathrm{sg}}$ after incubation with $1 \mathrm{mM}$ concentrations of different additives. The activity of the enzyme in the absence of additives was defined as $100 \%$. The experiments were done in triplicate. The mean value and the standard error are shown. Asteriks indicate a $p$ value $<0.05$. 
In addition to $\mathrm{TanB}_{\mathrm{Sg}}$ activity, the biochemical properties showed by Tan $\mathrm{A}_{\mathrm{Sg}}$ such as high specific activity, optimal temperature $\left(37^{\circ} \mathrm{C}\right)$ and broad $\mathrm{pH}$ range indicated that S. gallolyticus subsp. gallolyticus strains are so far the bacterial cells better adapted to degrade the tannins present on the diet. It has been described that S. gallolyticus initially responds to tannins with an increased lag phase and decreased growth rate [22]. The response mechanisms used by $S$. gallolyticus strains enables them to maintain growth and biosynthetic capacity in the presence of high tannin concentrations [22].

\section{Conclusions}

In summary, this study confirmed among bacteria the specific characteristics present in S. gallolyticus subsp. gallolyticus strains which could be important for survival in the gut environment of herbivores, where a large diversity of tannins is present. S. gallolyticus subsp. gallolyticus should be able to degrade these polyphenols and it is known that this bacterium does not depend on other microorganisms for their degradation. The tannin degradation pathway followed by $S$. gallolyticus subsp. gallolyticus strains implies the combined action of tannase and gallate decarboxylase, which are close on S. gallolyticus genome and seems to act coordinately. In addition, the presence in all the S. gallolyticus subsp. gallolyticus strains of a second, inducible and extracellular tannase enzyme provide them additional advantages for the degradation of high-molecular tannins. The specific features showed by $S$. gallolyticus subsp. gallolyticus in relation to tannin degradation suggested that these strains are the best bacterial factories for tannin degradation described so far. This explains the widespread occurrence of S. gallolyticus in the rumen of livestock that frequently browse tannin-containing forages, and it is likely that the presence of S. gallolyticus provides a selective advantage to these animals.

\section{Materials and methods}

\section{Bacterial strains and growth conditions}

S. gallolyticus subsp. gallolyticus UCN34 (CIP 110142) used through this study was kindly provided by Dr. Philippe Glaser (Institut Pasteur, France). S. gallolyticus DSM 13808, S. gallolyticus subsp. gallolyticus DSM $16831^{\mathrm{T}}$, S. gallolyticus subsp. pasteurianus DSM $15351^{\mathrm{T}}$, and S. gallolyticus subsp. macedonius DSM $15879^{\mathrm{T}}$ were purchased from the German Collection of Microorganisms and Cell Cultures (DSMZ). Escherichia coli DH10B and $E$. coli BL21 (DE3) were used as transformation and expression hosts in the pURI3-TEV vector [23]. The $S$. gallolyticus strains were grown in BHI medium at $37^{\circ} \mathrm{C}$ without shaking, and the E. coli strains were cultured in Luria-Bertani (LB) medium at $37^{\circ} \mathrm{C}$ and shaking at $200 \mathrm{rpm}$.

\section{PCR detection of tannase encoding genes}

Genes encoding $S$. gallolyticus tannases $\left(\tan A_{S g}\right.$ and $\tan B_{S g}$ ) were amplified by PCR using chromosomal DNA from $S$. gallolyticus strains. The $\tan A_{S g}$ gene $(1.7 \mathrm{~kb})$ was amplified by using primers 803 and 804 (Additional file 3 : Table S2). Oligonucleotides 774 and 775 were used to amplify $\tan B_{S g}$ gene $(1.4 \mathrm{~kb})$. The reactions were performed in a Personal thermocycler (Eppendorf), using 30 cycles of denaturation at $94^{\circ} \mathrm{C}$ for $30 \mathrm{~s}$, annealing at $55^{\circ} \mathrm{C}$ for $1 \mathrm{~min}$, and extension at $72^{\circ} \mathrm{C}$ for $2 \mathrm{~min}$. Amplified fragments were resolved in agarose gels.

\section{Quantitative PCR}

For RNA isolation, BHI cultures of S. gallolyticus subsp. gallolyticus UCN34 were grown up to an OD $600_{\mathrm{nm}}$ of 1 and then supplemented with methyl gallate at $15 \mathrm{mM}$ final concentration. As control, RNA was also isolated from cultures not supplemented with methyl gallate. The induced cells and their corresponding controls were centrifuged at $4^{\circ} \mathrm{C}$ after $10 \mathrm{~min}$ of exposure to the gallate ester. The pellet was mixed with $2 \mathrm{~mL}$ of quenching buffer $\left(60 \%\right.$ methanol, $66.7 \mathrm{mM}$ HEPES, $\left.\mathrm{pH} 6.5,-40^{\circ} \mathrm{C}\right)$. Following quenching, the cells were centrifuged at 9,000 $\times \mathrm{g}$ for $10 \mathrm{~min}$ at $-10^{\circ} \mathrm{C}$ and suspended in an extraction mixture $(500 \mu \mathrm{L} 1: 4$ chloroform-acid phenol, $30 \mu \mathrm{L}$ of $10 \%$ SDS, $30 \mu \mathrm{L}$ Na-acetate $3 \mathrm{M} \mathrm{pH} 5.2,400 \mu \mathrm{L}$ Tris-EDTA buffer [10 mM Tris(hydroxymethyl)amino methane, $1 \mathrm{mM}$ EDTA] $\mathrm{pH} 7.4,15 \mathrm{mg}$ of polyvinylpolypyrrolidone, and $500 \mathrm{mg}$ of glass beads ( $\phi, 75-150 \mu \mathrm{m})$. The cells were broken under frozen conditions in a Mini-Bead Beater (Biospec Products, INC.) using three treatments of $4600 \mathrm{rpm}$ for 40 seconds and chilled $1 \mathrm{~min}$ between cycles. The suspension was then centrifuged at $4^{\circ} \mathrm{C}$ at $10,000 \times \mathrm{g}$ for $2 \mathrm{~min}$. After two extractions with $500 \mu \mathrm{L}$ of chloroform the supernatant containing the RNA was immediately frozen in liquid nitrogen, and stored at $-80^{\circ} \mathrm{C}$. NanoDrop ND1000 instrument was used for quantification of RNA. The $A_{260} / A_{280}$ and $A_{260} / A_{230}$ ratios were measured to check RNA purity. Integrity and quality of RNA samples were determined by electrophoresis on agarose gels. Two treatments with DNase I (Ambion) were applied and the absence of genomic DNA was confirmed by PCR [24]. The DNA-free RNA was reverse transcribed using the High Capacity cDNA Reverse Transcription Kit (Applied Biosyntems) according to the manufacturer instructions. From the cDNA obtained, quantitative gene expression was analyzed in an AbiPrism 7500 Fast Real Time PCR system (Applied Biosystems). The SYBR Green method was used and each assay was performed in triplicate using SYBR Green real-time PCR Master Mix (Applied Biosystems). Amplification was initiated at $95^{\circ} \mathrm{C}$ for $10 \mathrm{~min}$, followed by 40 cycles of $95^{\circ} \mathrm{C}$ for $15 \mathrm{~s}$ and $60^{\circ} \mathrm{C}$ for $1 \mathrm{~min}$. Control PCRs were included to confirm the absence of primer dimer formation 
(no-template control), and to verify that there was no DNA contamination (without RT enzyme negative control). Specific primer pairs were designed with the Primer Express 3.0 program to amplify internal regions of tannase and gallate decarboxylase encoding genes (Additional file 3: Table S2). All qPCR assays amplified a single product as determined by melting curve analysis and by electrophoresis. A standard curve was plotted with cycle threshold (Ct) values obtained from amplification of known quantities of cDNA and used to determine the efficiency (E) as $\mathrm{E}=10^{-1 / \text { slope }}$. In order to measure $S$. gallolyticus gene expression, amplification of the endogenous control gene was performed simultaneously and its relative expression compared with that of the target gene. Results were analyzed using the comparative $\mathrm{Ct}$ method (also named double delta-delta Ct, $2^{\Delta \Delta C t}$ method). Genes were considered differentially expressed when a nominal p-values were $<0.1$ and had a fold change $(\mathrm{FC}) \geq 2$. Relative expression levels were calculated with the 7500 Fast System relative quantification software using $S$. gallolyticus $16 S$ rRNA gene as endogenous gene and the growth in the absence of methyl gallate as growth condition calibrator.

\section{Cloning, expression and purification of $\operatorname{Tan} A_{S g}$ from S. gallolyticus UCN34}

The gene encoding a putative tannase (GALLO_0933, or $\tan A_{S g}$ ) in S. gallolyticus UCN34 (accession YP_003430356) was PCR-amplified by PrimeSTAR HS DNA polymerase (Takara). As a peptide signal was predicted in the Tan $\mathrm{A}_{\mathrm{Sg}}$ sequence, primers 803 and 804 were used to amplify and clone $\mathrm{Tan}_{\mathrm{Sg}}$ lacking the 26-amino acid peptide signal sequence. The gene was cloned into the pURI3-TEV vector which encodes expression of a leader sequence containing a six-histidine affinity tag. The purified $1.7-\mathrm{kb}$ PCR product was then inserted into the vector by using a restriction enzyme- and ligation-free cloning strategy [23].

E. coli DH10B cells were transformed, recombinant plasmids were isolated, and those containing the correct insert were identified by restriction enzyme analysis, verified by DNA sequencing, and then transformed into E. coli BL21 (DE3) cells for expression. E. coli BL21 (DE3) cells carrying the recombinant plasmid, pURI3TEV-Tan $A_{S g}$, were grown at $37^{\circ} \mathrm{C}$ in $\mathrm{LB}$ media containing ampicillin $(100 \mu \mathrm{g} / \mathrm{ml})$ on a rotary shaker $(200 \mathrm{rpm})$ until an optical density at $600 \mathrm{~nm}$ of 0.4 was reached. Isopropyl- $\beta$-D-thiogalactoside (IPTG) was added to a final concentration of $0.4 \mathrm{mM}$ and protein induction was continued at $22^{\circ} \mathrm{C}$ for $18 \mathrm{~h}$.

The induced cells were harvested by centrifugation $\left(8,000 \mathrm{~g}, 15 \mathrm{~min}, 4^{\circ} \mathrm{C}\right)$, resuspended in phosphate buffer (50 mM, pH 6.5) and disrupted by French Press passages (three times at 1,100 psi). The insoluble fraction of the lysate was removed by centrifugation at $47,000 \mathrm{~g}$ for $30 \mathrm{~min}$ at $4^{\circ} \mathrm{C}$. The supernatant was filtered through a
$0.2 \mu \mathrm{m}$ pore-size filter and then applied to a Talon Superflow resin (Clontech) equilibrated in phosphate buffer (50 mM, pH 6.5) containing $3 \mathrm{mM} \mathrm{NaCl}$ and $10 \mathrm{mM}$ imidazole to improve the interaction specificity in the affinity chromatography step. The bound enzyme was eluted using $150 \mathrm{mM}$ imidazole in the same buffer. The purity of the enzymes was determined by SDSPAGE in Tris-glycine buffer. Fractions containing the His6-tagged protein were pooled and analyzed for tannase activity.

\section{Tannase activity assay}

Tannase activity was determined using a rhodanine assay specific for gallic acid [21]. Rhodanine reacts only with gallic acid and not with galloyl esters or other phenolics. Gallic acid analysis in the reactions was determined using the following assay. Tannase enzyme $(100 \mu \mathrm{g})$ in $700 \mu \mathrm{l}$ of $50 \mathrm{mM}$ phosphate buffer $\mathrm{pH} 6.5$ was incubated with $40 \mu \mathrm{l}$ of $25 \mathrm{mM}$ methyl gallate $(1 \mathrm{mM}$ final concentration) for $5 \mathrm{~min}$ at $37^{\circ} \mathrm{C}$. After this incubation, $150 \mu \mathrm{l}$ of a methanolic rhodanine solution $(0.667 \% \mathrm{w} / \mathrm{v}$ rhodanine in $100 \%$ methanol) were added to the mixture. After $5 \mathrm{~min}$ incubation at $30^{\circ} \mathrm{C}, 100 \mu \mathrm{l}$ of $500 \mathrm{mM} \mathrm{KOH}$ was added. After an additional incubation of 5-10 min, the absorbance at $520 \mathrm{~nm}$ was measured on a spectrophotometer. A standard curve using gallic acid concentration ranging from 0.125 to $1 \mathrm{mM}$ was prepared. One unit of tannase activity was defined as the amount of enzyme required to release $1 \mu \mathrm{mol}$ of gallic acid per minute under standard reaction conditions.

\section{Biochemical properties of $\operatorname{Tan}_{\mathrm{Sg}}$ tannase}

The $\mathrm{pH}$ profile of Tan $\mathrm{A}_{\mathrm{Sg}}$ activity was determined using different $100 \mathrm{mM}$ buffer systems containing acetic acidsodium acetate $(\mathrm{pH} 3.0-5.0)$, citric acid-sodium citrate ( $\mathrm{pH}$ 6), sodium phosphate ( $\mathrm{pH} 7)$, Tris- $\mathrm{HCl}(\mathrm{pH} 8)$, glycine$\mathrm{NaOH}$ ( $\mathrm{pH}$ 9), and sodium carbonate-bicarbonate $(\mathrm{pH} 10)$. The rhodanine assay was used for the optimal pH characterization of tannase. Since the rhodaninegallic acid complex forms only in basic conditions, after the completion of the enzymatic degradation of methyl gallate, $\mathrm{KOH}$ was added to the reaction mixture to ensure that the same $\mathrm{pH}$ value $(\mathrm{pH} 11)$ was achieved in all samples assayed. Determinations were done in triplicate.

The optimal temperature for purified Tan $A_{S g}$ tannase was determined in the temperature range $4-65^{\circ} \mathrm{C}$ in $25 \mathrm{mM}$ phosphate buffer ( $\mathrm{pH}$ 6.5). For determination of the thermal stability of Tan $\mathrm{A}_{\mathrm{Sg}}$, the enzyme in $50 \mathrm{mM}$ phosphate buffer $\mathrm{pH} 6.5$ was preincubated in the absence of substrate at $22,30,37,45,55$ and $65^{\circ} \mathrm{C}$ for $30 \mathrm{~min}$ and 2, 4, 6, and $18 \mathrm{~h}$. Aliquots were withdrawn in triplicate at these incubation times to test the remaining activity under standard conditions. The residual tannase activity 
was determined at $37^{\circ} \mathrm{C}$. The non-heated enzyme was considered as control (100\%).

The enzyme was pre-incubated in the presence of various metal salts and chemical agents using final concentrations of $1 \mathrm{mM}$. The effect of chemical inhibitors and stimulators on Tan $\mathrm{A}_{\mathrm{Sg}}$ activity was investigated in triplicate by the rhodanine assay using methyl gallate as substrate. The additives analyzed were $\mathrm{MgCl}_{2}, \mathrm{KCl}, \mathrm{CaCl}_{2}$, $\mathrm{HgCl}_{2}, \mathrm{ZnCl}_{2}$, Triton X-100, Urea, Tween 80, EDTA, DMSO, and $\beta$-mercaptoethanol. The extent of inhibition or activation of tannase activity was indicated as the percentage of the ratio of residual activity to complete enzyme activity in the control sample without addition of metal ions or chemical agents. Tannase activity measured in the absence of any additive was used as control (100\%).

The substrate specificity of Tan $\mathrm{A}_{\mathrm{Sg}}$ was determined using 17 commercial phenolic esters (methyl gallate, ethyl gallate, propyl gallate, lauryl gallate, methyl benzoate, ethyl benzoate, methyl 4-hydroxybenzoate, ethyl 4-hydroxybenzoate, propyl 4-hydroxybenzoate, butyl 4-hydroxybenzoate, methyl vanillate, methyl 2, 4-dihydroxybenzoate, methyl gentisate, methyl salicylate, ethyl 3, 4-dihydroxybenzoate, ferulic methyl ester, and ferulic ethyl ester) as well as a natural tannins (epigallocatechin gallate, and tannic acid). As controls, phosphate buffer $(50 \mathrm{mM}, \mathrm{pH} 7.0)$ containing thereagents but lacking the enzyme were incubated in the same conditions.

The hydrolysis products were extracted twice with ethyl acetate (Lab-Scan, Ireland) and analyzed by HPLCDAD. A Thermo (Thermo Electron Corporation, Waltham, Massachussetts, USA) chromatograph equipped with a P4000 SpectraSystem pump, and AS3000 autosampler, and a UV6000LP photodiode array detector were used. A gradient of solvent A (water/acetic acid, 98:2, v/v) and solvent B (water/acetonitrile/acetic acid, 78:20:2, v/v/v) was applied to a reversed-phase Nova-pack $\mathrm{C}_{18}(25 \mathrm{~cm} \times$ $4.0 \mathrm{~mm}$ i.d.) $4.6 \mu \mathrm{m}$ particle size, cartridge at room temperature as follows: $0-55 \mathrm{~min}, 80 \% \mathrm{~B}$ linear, $1.1 \mathrm{ml} /$ min; 55-57 $\mathrm{min}, 90 \%$ B linear, $1.2 \mathrm{ml} / \mathrm{min}$; 57-70 $\mathrm{min}, 90 \%$ $\mathrm{B}$ isocratic, $1.2 \mathrm{ml} / \mathrm{min}$; $70-80 \mathrm{~min}, 95 \% \mathrm{~B}$ linear, $1.2 \mathrm{ml} /$ $\mathrm{min}$; $80-90 \mathrm{~min}, 100 \%$ linear, $1.2 \mathrm{ml} / \mathrm{min}$; $100-120 \mathrm{~min}$, washing $1.0 \mathrm{ml} / \mathrm{min}$, and reequilibration of the column under initial gradient conditions. Detection was performed by scanning from 220 to $380 \mathrm{~nm}$. Samples were injected onto the cartridge after being filtered through a $0.45 \mu \mathrm{m}$ PVDF filter.

\section{Statistical analyses}

Two-tailed Student's test performed using GraphPad InStat, version 3.0 (GraphPad Software, San Diego, CA) was used to determine the differences between means. The data are representative means of at least three independent experiments.

\section{Additional files}

Additional file 1: Figure S1. Comparison of amino acid sequences of bacterial tannases. (A) TanA $A_{S I}$ from Staphylococcus lugdunensis, TanA $A_{L p}$ and $T a n B_{L p}$ from Lactobacillus plantarum, and Tan $A_{S g}$ and $T a n B_{S g}$ from Streptococcus gallolyticus subsp. gallolyticus. (B) Alignment of TanA or (C) TanB proteins. Multiple alignments were done using the program ClustalW2 after retrieval of sequences from BLAST homology searches. Residues that are identical $(*)$, conserved (:) or semiconserved (.) in all sequences are indicated. Dashes indicated gaps introduced to maximize similarities. The vertical line indicated the predicted peptide signal cleavage site. The serine hydrolase conserved motif is highlighted in yellow; residues of the catalytic triad identified in the structure of TanB $B_{L p}$ are highlighted in blue; and residues which make contacts with the three hydroxyl groups of gallic acid are highlighted in pink color.

Additional file 2: Table S1. Characteristics of S. gallolyticus tannases. Additional file 3: Table S2. Primers used for PCR and $q P C R$ analysis.

\section{Competing interests}

The authors declare that they have no competing interests.

\section{Authors' contributions}

NJ, IR and MET performed the experiments and drafted the manuscript. FLF, $\mathrm{BR}$ and RM participated in the design of the study and supervised the study. All authors revised and approved the final manuscript.

\section{Acknowledgements}

This work was financially supported by grants AGL2011-22745, S2009/AGR-1469 (ALIBIRD) (Comunidad de Madrid), and RM2012-00004 (INIA). We acknowledge support of the publication fee by the CSIC Open Access Publication Support Initiative through its Unit of Information Resources for Research (URICI). We are grateful to J. M. Barcenilla and M. V. Santamaría for their assistance. N. Jiménez is a recipient of a FPI fellowship from the MINECO and M. Esteban-Torres is a recipient of a JAE predoctoral fellowship from the CSIC.

Received: 30 September 2014 Accepted: 20 October 2014

Published online: 31 October 2014

\section{References}

1. Serrano J, Puupponen-Pimiä R, Dauer A, Aura A-M, Saura-Calixto F: Tannins: current knowledge of food sources, intake, bioavailability and biological effects. Mol Nutr Food Res 2009, 53:S310-S329.

2. Mingshu L, Kai Y, Quiang H, Dongying J: Biodegradation of gallotannins and ellagitannins. J Basic Microbiol 2006, 46:68-84.

3. Barry TN, Manley TR: Interrelationships between the concentrations of total condensed tannin, free condensed tannin and lignin in Lotus sp. and their possible consequences in ruminant nutrition. J Sci Food Agric 1986, 37:248-254.

4. Krause DO, Smith WJM, Broker JD, MCSweeney CS: Tolerance mechanisms of streptococci to hydrolysable and condensed tannins. Anim Feed Sci Tech 2005, 121:59-75.

5. Osawa R, Fujisawa T, Sly LI: Streptococcus gallolyticus sp. nov.; gallate degrading organisms formerly assigned to Streptococcus bovis. System Appl Microbiol 1995, 18:74-78.

6. Sly LI, Cahill M, Osawa R, Fujisawa T: The tannin-degrading species Streptococcus gallolyticus and Streptococcus caprinus are subjective synonyms. Int J Syst Bacteriol 1997, 47:893-894.

7. Sasaki E, Shimada T, Osawa R, Nishitani Y, Spring S, Lang E: Isolation of tannin-degrading bacteria isolated from feces of the Japanese large wood mouse, Apodemus speciosus, feeding on tannin-rich acorns. Syst Appl Microbiol 2005, 28:358-365.

8. Chamkha M, Patel BKC, Traore A, Garcia JL, Labat M: Isolation from a shea cake digester of a tannin-degrading Streptococcus gallolyticus strain that decarboxylates protocatechuic acid hydroxycinnamic acids, and emendation of the species. Int J System Evol Microbiol 2002, 52:939-944.

9. Iwamoto K, Tsuruta H, Nishitaini Y, Osawa R: Identification and cloning of a gene encoding tannase (tannin acylhydrolase) from Lactobacillus plantarum ATCC $14917^{\top}$. Syst Appl Microbiol 2008, 31:269-277. 
10. Jiménez N, Curiel JA, Reverón I, de las Rivas B, Muñoz R: Uncovering the Lactobacillus plantarum WCFS1 gallate decarboxylase involved in tannin degradation. Appl Environ Microbiol 2013, 79:4253-4263.

11. Jiménez N, Esteban-Torres M, Mancheño JM, de las Rivas B, Muñoz R: Tannin degradation by a second tannase enzyme present in some Lactobacillus plantarum strains. Appl Environ Microbiol 2014, 80:2991-2997.

12. Rusniok C, Couvé E, da Cunha V, El Gana R, Zidane N, Bouchier C, Poyart C, Leclercq R, Trieu-Cuot P, Glaser P: Genome sequence of Streptococcus gallolyticus: insights into its adaptation to the bovine rumen and its ability to cause endocarditis. J Bacteriol 2010, 192:2266-2276.

13. Chávez-González M, Rodríguez-Durán LV, Balagurusamy N, Prado-Barragán A, Rodríguez R, Contreras JC, Aguilar CN: Biotechnological advances and challenges of tannase: an overview. Food Bioprocess Technol 2012, 5:445-459.

14. Jiménez N, Barcenilla JM, López de Felipe F, de las Rivas B, Muñoz R: Characterization of a bacterial tannase from Streptococcus gallolyticus UCN34 suitable for tannin biodegradation. Appl Microbiol Biotechnol 2014, 98:6329-6337.

15. Noguchi N, Ohashi T, Shiratori T, Narui K, Hagiwara T, Ko M, Watanabe K, Miyahara T, Taira S, Moriyasu F, Sasatsu M: Association of tannase-producing Staphylococcus lugdunensis with colon cancer and characterization of a novel tannase gene. J Gastroenterol 2007, 42:346-351.

16. Schlegel L, Grimont F, Ageron E, Grimont PAD, Bouvet A: Reappraisal of the taxonomy of the Streptococcus bovis/Streptococcus equinus complex and related species: description of Streptococcus gallolyticus subsp. gallolyticus subsp. nov., S. gallolyticus subsp. macedonius subsp. nov. and S. gallolyticus subsps. pasteurianus subsp. nov. Int I System Evol Microbiol 2003, 53:631-645.

17. Ren B, Wu M, Wang Q, Peng X, Wen H, McKinstry WJ, Chen Q: Crystal structure of tannase from Lactobacillus plantarum. J Mol Biol 2013, 425:2737-2751.

18. Curiel JA, Rodríguez H, Acebrón I, Mancheño JM, de las Rivas B, Muñoz R: Production and physicochemical properties of recombinant Lactobacillus plantarum tannase. J Agric Food Chem 2009, 57:6224-6230.

19. Hakkinen SH, Torronen AR: Content of flavonols and selected phenolic acids in strawberries and Vaccinium species: Influence of cultivar, cultivation site and technique. Food Res Int 2000, 33:517-524.

20. Mueller-Harvey I: Analysis of hydrolysable tannins. Animal Feed Sci Technol 2001, 91:3-20.

21. Inoue $\mathrm{KH}$, Hagerman AE: Determination of gallotannins with rhodanine. Anal Biochem 1988, 169:363-369.

22. O'Donovan L, Brooker JD: Effect of hydrolysable and condensed tannins on growth, morphology and metabolism of Streptococcus gallolyticus (S. caprinus) and Streptococcus bovis. Microbiology 2001, 147:1025-1033.

23. Curiel JA, de las Rivas $B$, Mancheño JM, Muñoz R: The pURI family of expression vectors: a versatile set of ligation independent cloning plasmids for producing recombinant His-fusion proteins. Prot Expr Purif 2011, 76:44-53.

24. Saulnier DM, Molenaar D, de Vos WM, Gibson GR, Kolida S: Identification of prebiotic fructooligosaccharide metabolism in Lactobacillus plantarum WCFS1 through microarrays. Appl Environ Microbiol 2007, 73:1753-1765.

doi:10.1186/s12934-014-0154-8

Cite this article as: Jiménez et al:: Genetic and biochemical approaches towards unravelling the degradation of gallotannins by Streptococcus gallolyticus. Microbial Cell Factories 2014 13:154.

\section{Submit your next manuscript to BioMed Central and take full advantage of:}

- Convenient online submission

- Thorough peer review

- No space constraints or color figure charges

- Immediate publication on acceptance

- Inclusion in PubMed, CAS, Scopus and Google Scholar

- Research which is freely available for redistribution

Submit your manuscript at www.biomedcentral.com/submit 